\title{
Fontes de óleo e níveis de suplementação de vitamina E na ração sobre a qualidade do sêmen suíno acondicionado a 17 e $5^{\circ} \mathrm{C}$
}

\author{
Elenice Andrade Moraes ${ }^{1 *}$, Ciro Alexandre Alves Torres $^{1}$, José Domingos Guimarães ${ }^{1}$, \\ Giovanni Ribeiro de Carvalho ${ }^{1}$, Luis David Solis Murgas ${ }^{2}$, Eduardo Paulino da Costa ${ }^{1}$
}

1 Universidade Federal de Viçosa (UFV) - Viçosa, MG.
2 Universidade Federal de Lavras (UFLA) - Lavras, MG.

RESUMO - Objetivou-se avaliar o efeito da adição de fontes de óleo e dos níveis de suplementação de vitamina E na ração sobre as características do sêmen suíno resfriado a $17^{\circ} \mathrm{C}$ e $5^{\circ} \mathrm{C}$. Foram utilizados 24 suínos machos reprodutores Dalboar 85 distribuídos em delineamento inteiramente casualizado, em arranjo fatorial $2 \times 3$, com duas fontes de óleo (soja e salmão) e três níveis de antioxidantes $(150,300$ e $450 \mathrm{mg}$ de vitamina E/ kg). Nos animais sob suplementação com óleo de salmão, a motilidade e o teste hiposmótico dos espermatozoides após 24, 48 e 72 horas foram superiores aos observados nos animais alimentados com a ração com óleo de soja. O óleo de salmão aumentou o vigor em ambas as temperaturas avaliadas após 24 e 48 horas. A ocorrência de anormalidades morfológicas totais foi maior no sêmen dos animais sob suplementação com óleo de soja e resfriado a $17^{\circ} \mathrm{C}$, enquanto na menor temperatura de resfriamento $\left(5^{\circ}\right)$ não houve diferença entre os animais sob suplementação. A morfologia anormal no sêmen a $5^{\circ} \mathrm{C}$ foi maior que no sêmen resfriado a $17^{\circ} \mathrm{C}$. $\mathrm{O}$ óleo de salmão melhora as características espermáticas do sêmen suíno resfriado a 17 e $5^{\circ} \mathrm{C}$ durante 24 a 48 horas.

Palavras-chave: ácidos graxos poliinsaturados, características seminais, espermatozoides, óleo de salmão, resfriamento

\section{Oil sources and levels of vitamin E supplementation in the diet on the quality of boar semen cooled at 17 and $5^{\circ} \mathrm{C}$}

\begin{abstract}
The objective of this study was to evaluate the effect of the addition of oil sources and levels of vitamin E supplementation in the rations on the characteristics of boar semen cooled at 17 and $5^{\circ} \mathrm{C}$. It was used twenty-four Dalboar 85 boars distributed in a complete random design, in a $2 \times 3$ factorial scheme, with two sources of oil (soybean and salmon) and three levels of antioxidant $(150,300$ and 450 vitamin $\mathrm{E} \mathrm{mg} / \mathrm{kg}$ ). For animals under supplementation with salmon oil, the motility and hypoosmotic swelling test (HOST) of sperm after 24, 48, and 72 hours was higher than the ones observed in animals fed soybean oil ration. Salmon oil increased the vigor in both temperatures evaluated after 24 and 48 hours. The occurence of total morphological abnormalities was higher in the semen of animals fed soybean oil and cooled at $17^{\circ} \mathrm{C}$ while in the lowest cooling temperature $\left(5^{\circ} \mathrm{C}\right)$ there was no difference among animals under supplementation. The abnormal morphology in the semen at $5^{\circ} \mathrm{C}$ was higher than in the semen cooled at $17^{\circ} \mathrm{C}$. Salmon oil improves the sperm characteristics of the boar semen cooled at 17 and $5^{\circ} \mathrm{C}$ from 24 to 48 hours.
\end{abstract}

Key Words: cooling, salmon oil, seminal characteristics, sperm, unsaturated fatty acid

\section{Introdução}

A membrana espermática apresenta uma composição mista de fosfolipídios que pode diferir de espécie para espécie, além da temperatura de transição de fase ser variável para cada tipo de fosfolipídio (Buhr et al., 1994). Durante o resfriamento, a separação lateral de fases pode ocorrer em função disso, há aumento da permeabilidade da membrana com perda de cátions e enzimas, redução da atividade enzimática e perturbações nos processos de difusão controlados pela membrana (De Leeuw et al., 1991). Além disso, durante o resfriamento, o desequilíbrio iônico intra e extracelular pode reduzir a motilidade espermática (Watson, 1996).

A temperatura de armazenamento do sêmen suíno, entre 15 e $18^{\circ} \mathrm{C}$, não interrompe totalmente o metabolismo dos espermatozoides, cujos metabólitos produzidos se acumulam e interferem na motilidade espermática. Nessa temperatura ainda há multiplicação bacteriana, que pode afetar a qualidade do sêmen. Teoricamente, quanto mais baixa a temperatura de armazenamento, menor será o metabolismo e maior poderá ser o tempo de armazenamento

Recebido em 18/8/2008 e aprovado em 18/6/2009.

Correspondências devem ser enviadas para: eamufv@yahoo.com.br

* Endereço atual: Universidade Federal do Vale do São Francisco (UNIVASF) - Petrolina, PE. 
do sêmen. $\mathrm{O}$ armazenamento do sêmen suíno em temperaturas próximas a $5^{\circ} \mathrm{C}$ seria uma vantagem, visto que poderia permanecer estocado em refrigeradores domésticos (Landsverk, 2000), de conveniência para a maioria dos produtores. No entanto, o espermatozoide suíno é sensível a temperaturas inferiores a $15^{\circ} \mathrm{C}$, abaixo da qual há redução da motilidade (Johnson et al., 2000). Sabe-se que na faixa de temperatura de $25^{\circ} \mathrm{C}$ a $5^{\circ} \mathrm{C}$ ocorre a redução da fluidez dos lipídios da membrana do espermatozoide suíno, o que poderia explicar sua maior sensibilidade ao resfriamento (Buhr et al., 1994).

Weber (1989), ao estudar o armazenamento do sêmen suíno a $5^{\circ} \mathrm{C}$, verificou que a colocação direta a $5^{\circ} \mathrm{C}$ causa queda brusca da motilidade e do percentual de acrossomas normais. Em outros estudos desenvolvidos para viabilizar o acondicionamento do sêmen suíno em temperaturas inferiores a $15^{\circ} \mathrm{C}$ evidenciou-se que os efeitos relacionados ao choque térmico foram amenizados quando o sêmen permanecia por certo período incubado em temperaturas acima de $15^{\circ} \mathrm{C}$ (Pursel et al., 1972; Tamuli e Watson, 1994). Além disso, foi verificado que o resfriamento gradual resulta em maior viabilidade espermática que o resfriamento direto (Weitze et al., 2000). Assim, objetivou-se avaliar o efeito de fontes de óleo e níveis de suplementação de vitamina $\mathrm{E}$ sobre as características do sêmen resfriado a 17 e $5^{\circ} \mathrm{C}$ após 24, 48 e 72 horas de acondicionamento.

\section{Material e Métodos}

O período de coleta de dados para avaliação dos animais e sua seleção, bem como o experimento, ocorreu entre os meses de setembro de 2005 a janeiro de 2006, nas dependências do Centro de Difusão Genética da Perdigão Agroindustrial S/A (Videira/SC).

Foram utilizados 24 suínos machos reprodutores Dalboar $85^{\circledR}$ (Topig do Brasil), com idades entre 12 e 18 meses, alojados em baias individuais com água à vontade e suplementação concentrada diária $(2,5 \mathrm{~kg})$, segundo exigências estabelecidas pelo NRC (1998). Os animais foram alojados segundo delineamento experimental inteiramente ao acaso, em arranjo fatorial $2 \times 3$ (óleo soja ou salmão; e 150, 300 e 450 mg de vitamina $\mathrm{E} / \mathrm{kg}$ de ração), por um período experimental de dez semanas. Foram adicionados 3,5\% de óleo às dietas, independentemente da fonte utilizada.

Os ácidos graxos presentes nas rações foram extraídos pela técnica preconizadas por Folch et al. (1957) e a composição de ácidos graxos identificados foi determinada por cromatografia gasosa segundo Firestone (1998). A avaliação do perfil de ácidos graxos e o teor de vitamina $\mathrm{E}$ nos espermatozoides foram realizados na $1^{\mathrm{a}}, 4^{\mathrm{a}}, 7^{\mathrm{a}} \mathrm{a}$ e $10^{\mathrm{a}}$ semanas do período experimental. O protocolo utilizado no preparo do sêmen para extração de ácidos graxos foi descrito por Rooke et al. (2001). A composição das dietas é apresentada na Tabela 1. Para análise do perfil de ácidos graxos utilizou-se o protocolo recomendado por Blesbois et al. (1997) (Tabelas 2 e 3 ).

Tabela 1 - Composição da dieta experimental

\begin{tabular}{lc}
\hline Ingrediente & Quantidade (kg) \\
\hline Milho & 66,05 \\
Farelo de soja & 19,40 \\
Casca de soja & 7,38 \\
Óleo & 3,50 \\
Fosfato bicálcico & 1,63 \\
Calcário & 0,87 \\
Sal & 0,45 \\
Premix de vitaminas e minerais ${ }^{2}$ & 0,40 \\
Adsorvente de micotoxinas ${ }^{3}$ & 0,20 \\
Lisina & 0,13 \\
Matéria seca (\%) & 87,53 \\
Energia metabolizável (kcal/kg) & 3.555 \\
Proteína bruta (\%) & 17,3 \\
Fibra (\%) & 4,60 \\
Cálcio (\%) & 0,79 \\
Fósforo disponível (\%) & 0,45 \\
Gordura (\%) & 6,59 \\
Metionina (\%) & 0,237 \\
Metionina + cistina (\%) & 0,503 \\
Lisina (\%) & 0,799 \\
\hline Óleos de soja e salmão foram adicionados na mesma proporção. & \\
2 Premix vitamínico e mineral suíno reprodução $0,4 \%$ & Mordigão \\
3 Mycofix ${ }^{\circledR}-$ Biomin. &
\end{tabular}

Tabela 2 - Composição de ácidos graxos identificados nas dietas experimentais

\begin{tabular}{|c|c|c|}
\hline \multirow[t]{2}{*}{ Ácido graxo (\%) } & \multicolumn{2}{|c|}{ Fonte de óleo } \\
\hline & Soja $(\%)$ & Salmão (\%) \\
\hline C14:0 (ácido mirístico) & ND & 2,54 \\
\hline C16:0 (ácido palmítico) & 13,1 & 16,54 \\
\hline C16:1 (ácido palmitoleico) & 0,21 & 3,06 \\
\hline C18:0 (ácido esteárico) & 5,22 & 4,39 \\
\hline 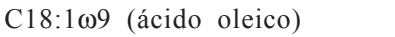 & 28,74 & 26,81 \\
\hline 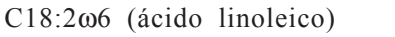 & 46,8 & 31,03 \\
\hline C18:3w3 (ácido linolênico) & 5,33 & 1,89 \\
\hline C20:0 (ácido araquídico) & 1,89 & 0,46 \\
\hline 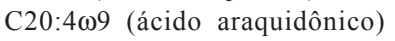 & 0,35 & 0,23 \\
\hline $\mathrm{C} 20: 5 \omega 3$ (EPA) & ND & 4,86 \\
\hline C22:1 19 (ácido erúcico) & 0,37 & 0,3 \\
\hline $\mathrm{C} 22: 5 \omega 3$ (DPA) & ND & 2,28 \\
\hline $\mathrm{C} 22: 6 \omega 3$ (DHA) & ND & 7,63 \\
\hline Saturados & 20,19 & 23,93 \\
\hline Monoinsaturados & 29,32 & 30,17 \\
\hline Poliinsaturados & 52,48 & 47,92 \\
\hline Ômega 6 & 47,15 & 31,27 \\
\hline Ômega 3 & 5,33 & 16,65 \\
\hline Ômega 6:ômega 3 & 8,85 & 1,88 \\
\hline Insaturados:saturados (I:S) & 4,05 & 3,26 \\
\hline
\end{tabular}

$\mathrm{ND}=$ não-detectado. 
Tabela 3 - Composição de ácidos graxos de espermatozoides de suínos sob suplementação com óleo e vitamina E

\begin{tabular}{|c|c|c|c|c|c|}
\hline \multirow{2}{*}{$\begin{array}{l}\text { Tipo de } \\
\text { óleo }\end{array}$} & \multicolumn{3}{|c|}{ Nível de vitamina $\mathrm{E}(\mathrm{mg} / \mathrm{kg})$} & \multirow[b]{2}{*}{ Média } & \multirow[b]{2}{*}{ CV $(\%)$} \\
\hline & 150 & 300 & 450 & & \\
\hline \multicolumn{6}{|c|}{ C18:109 - ácido oleico } \\
\hline Soja & 17,17 & 17,15 & 17,15 & 17,16 & \\
\hline Salmão & 17,2 & 17,17 & 17,17 & 17,18 & \\
\hline Média & 17,18 & 17,16 & 17,16 & & 37,5 \\
\hline \multicolumn{6}{|c|}{ 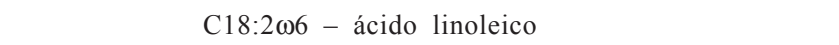 } \\
\hline Soja & 2,75 & 3,75 & 5,82 & 4,11 & \\
\hline Salmão & 2,57 & 2,77 & 5,52 & 3,42 & \\
\hline Média & 2,66 & 3,26 & 5,67 & & 17,9 \\
\hline \multicolumn{6}{|c|}{ 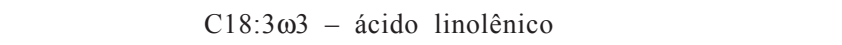 } \\
\hline Soja & 3,8 & 3,25 & 3,25 & 3,43 & \\
\hline Salmão & 3,75 & 3,25 & 3,18 & 3,39 & \\
\hline Média & 3,77 & 3,25 & 3,21 & & 47,5 \\
\hline \multicolumn{6}{|c|}{ 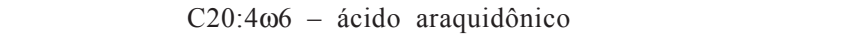 } \\
\hline Soja & 10,75 & 10,55 & 10,0 & 10,43 & \\
\hline Salmão & 9,50 & 9,55 & 9,40 & 9,48 & \\
\hline Média & 10,15 & 10,05 & 9,7 & & 44,2 \\
\hline \multicolumn{6}{|c|}{ C22:5 66 - docosapentanoico (DPA) } \\
\hline Soja & 24,85 & 25,03 & 24,85 & $24,91 \mathrm{a}$ & \\
\hline Salmão & 17,94 & 17,56 & 17,46 & $17,65 b$ & \\
\hline Média & 21,40 & 21,30 & 21,16 & & 19,6 \\
\hline \multicolumn{6}{|c|}{ C22:6 63 - ácido docosahexanoico (DHA) } \\
\hline Soja & 31,70 & 33,37 & 31,32 & $32,13 b$ & \\
\hline Salmão & 38,25 & 42,25 & 41,37 & $40,62 \mathrm{a}$ & \\
\hline Média & 34,97 & 37,81 & 36,35 & & 19,7 \\
\hline \multicolumn{6}{|c|}{ Ácidos graxos saturados } \\
\hline Soja & 61,70 & 63,37 & 64,32 & 63,13 & \\
\hline Salmão & 48,55 & 50,50 & 47,75 & 48,93 & \\
\hline Média & 55,12 & 56,93 & 56,03 & & 27,4 \\
\hline
\end{tabular}

a,b - Médias seguidas de letras diferentes na mesma linha/coluna diferiram $(\mathrm{P}<0,05)$ pelo teste SNK.

As amostras de sêmen foram coletadas, semanalmente (1 coleta/macho/semana, pelo método da mão enluvada (King \& Macpherson, 1973), em sala apropriada com um manequim. O sêmen foi coletado em copo plástico de $700 \mathrm{~mL}$ contido em um copo térmico, com água previamente aquecida a $37^{\circ} \mathrm{C}$. Imediatamente após a coleta do sêmen, o ejaculado foi analisado quanto a motilidade e vigor, conforme normas do CBRA (1998). O ejaculado foi diluído com Beltsville Thawing Solution (BTS), com 3 bilhões de espermatozoides totais em $100 \mathrm{~mL}$, sendo envasado em frascos plásticos, rotineiramente utilizadas na inseminação artificial, e fechados com tampas de plástico. Logo após o processo da diluição e envase, três garrafas (doses) de todos os animais suplementados foram acondicionadas em duas diferentes temperaturas: $17^{\circ} \mathrm{C}$ (câmara fria) e $5^{\circ} \mathrm{C}$ (geladeira de $280 \mathrm{~L}$ ), sem ter sido realizada anteriormente uma curva de resfriamento para o sêmen mantido a $5^{\circ} \mathrm{C}$. Após o armazenamento, a cada intervalo de 24 horas, em um total de 72 horas, uma garrafa plástica de cada amostra de sêmen dos animais suplementados foi retirada e dessa uma amostra de $2 \mathrm{~mL}$ foi retirada e transferida para um tubo de ensaio previamente aquecido e mantido em banho-maria a $37^{\circ} \mathrm{C}$ por 10 minutos, antes de sua avaliação (motilidade, vigor, morfologia e submetido ao teste hiposmótico).

A avaliação da motilidade total espermática foi expressa em porcentagem, e examinada em microscopia de contraste de fase em aumento de 200x, utilizando uma alíquota de $10 \mu \mathrm{L}$ de sêmen, depositada entre lâmina e lamínula, ambas mantidas a $37^{\circ} \mathrm{C}$. O vigor espermático, que é caracterizado pela intensidade da velocidade do movimento dos espermatozoides, foi avaliado em microscopia óptica de contraste de fase, em aumento de 200x. O vigor foi classificado de acordo com Ferreira Neto et al. (1977), variando de zero (0) a cinco (5), sendo o escore 0 equivalente à total imobilidade espermática e o escore 5 , à movimentação intensa, vigorosa, progressiva e com formação de ondas. Para a avaliação da morfologia espermática, utilizou-se a técnica de preparação úmida. Alíquotas de $10 \mu \mathrm{L}$ de sêmen foram adicionadas em $1 \mathrm{~mL}$ de formol-salino tamponado e estocadas à temperatura ambiente até análises. Foram contadas 100 células no microscópio óptico de contraste de fase no aumento de 1000x para a determinação do percentual de anormalidades espermáticas classificadas segundo CBRA (1998) dividindo as anormalidades em defeitos maiores e menores.

A funcionalidade da membrana plasmática (teste hiposmótico - HOST) foi avaliada no sêmen diluído resfriado, conforme a técnica da preparação úmida. $\mathrm{Na}$ solução à base de citrato de sódio e frutose $(0,9 \mathrm{~mL}) \mathrm{com}$ osmolaridade de $150 \mathrm{mOsmol} / \mathrm{L}$ (Vazquez et al., 1997) adicionou-se $10 \mu \mathrm{L}$ de sêmen diluído, e incubou-se por 30 minutos, em banho-maria, à $37^{\circ} \mathrm{C}$. Após esse período, alíquotas de $15 \mu \mathrm{L}$ da mistura foram colocadas entre lâmina e lamínula, para a contagem de 100 células de cada solução em microscopia de contraste de fase com aumento de 400x. As células foram classificadas quanto à presença ou não da cauda enrolada, segundo descrito por Kumi-Diaka (1993).

As análises dos parâmetros avaliados foram realizadas com utilização do programa SAEG (UFV, 1997). As variáveis foram submetidas aos testes de normalidade e homocedacidade. Posteriormente, foram submetidas à análise de variância dos dados e utilizaram o teste de Student Newman-Keuls (SNK) para comparação de médias entre as fontes de óleo, com nível de significância de 5\%, e análise de regressão para os níveis de antioxidantes usados. Quando houve interação, foi determinado o efeito do nível de antioxidante dentro de cada fonte. As variáveis que não atenderam às premissas para a análise de variância, 
mesmo após as transformações, foram submetidas ao teste não paramétrico de Wilcoxon.

\section{Resultados e Discussão}

Neste estudo, não foi observado efeito $(\mathrm{P}>0,05)$ do nível de vitamina $E$ nem dae sua interação com a fonte de óleo sobre nenhum dos parâmetros avaliados.

Os valores médios das características observadas neste estudo aproximam-se dos padrões de normalidade considerados para a espécie (CBRA, 1998).

$\mathrm{O}$ uso de sêmen suíno resfriado a $17^{\circ} \mathrm{C}$ é de uso rotineiro na suinocultura, ao passo que o resfriamento a $5^{\circ} \mathrm{C}$ ainda não é utilizado; em geral, é limitado por estar associado à menor fertilidade e à prolificidade devido a redução da motilidade e perda da integridade da membrana após o acondicionamento (De Leeuw et al., 1991). Além disso, o resfriamento a $5^{\circ} \mathrm{C}$ promove perdas de funções celulares, ligadas a motilidade (Watson \& Green, 2000). Por isso, avaliaram-se os efeitos das fontes de óleo adicionadas nas rações sobre a motilidade (Tabela 4), vigor (Tabela 5), HOST (Tabela 6) e morfologia anormal total (Tabela 7) do sêmen resfriado a 17 e $5^{\circ} \mathrm{C}$ após 24,48 e 72 horas de acondicionamento.

A motilidade espermática do sêmen dos animais tratados com óleo de salmão e resfriado a 17 e $5^{\circ} \mathrm{C}$ foi superior $(\mathrm{P}<0,05)$ à do sêmen de animais tratados com óleo de soja, para todos os períodos em que foram acondicionados (Tabela 4).

Os resultados corroboram os de Corrêa et al. (2005), que avaliaram o efeito do diluente PIGPEL-5 e BTS a $5^{\circ} \mathrm{C}$ após 24 horas de acondicionamento, e foram maiores que os valores reportados pelos autores após acondicionamento de 48 horas. Esses autores utilizaram amostras de sêmen diluídas com diluente BTS, porém tratados com diferentes fontes de ácidos graxos poliinsaturados, logo os resultados superaram os valores obtidos com um diluente desenvolvido especificamente para a temperatura de $5^{\circ} \mathrm{C}$. No entanto, Roner et al. (2005) observaram que a capacidade de preservação do sêmen suíno acondicionado a 17 e $5^{\circ} \mathrm{C}$ durante 72 horas foi inferior $(\mathrm{P}<0,05)$ às obtidas, para ambas as temperaturas, e verificaram motilidade para as temperaturas de 17 e $5^{\circ} \mathrm{C}$ de 63,7 e 55,7\%; 50,6 e 40,0\%; e 28, 1 e 10,6\% após 24,48 e 72 horas de acondicionamento, respectivamente.

Observaram-se valores de motilidade superiores aos reportados por Katzer et al. (2005), 43\% de motilidade, nas 48 horas de acondicionamento, após colocar o sêmen suíno diretamente a $5^{\circ} \mathrm{C}$ com diluente BTS. Esse valor de $43 \%$ seria inaceitável para seu uso na inseminação, e pode ser resultado da rápida velocidade de resfriamento utilizada. Entretanto,
Tabela 4 - Motilidade espermática do sêmen de suínos sob suplementação com óleo e vitamina $\mathrm{E}$

\begin{tabular}{|c|c|c|c|c|c|}
\hline \multirow{2}{*}{$\begin{array}{l}\text { Tipo de } \\
\text { óleo }\end{array}$} & \multicolumn{3}{|c|}{ Nível de vitamina E (mg/kg) } & \multirow[b]{2}{*}{ Média } & \multirow[b]{2}{*}{$\mathrm{CV}(\%)$} \\
\hline & 150 & 300 & 450 & & \\
\hline \multicolumn{6}{|c|}{ Motilidade a $17^{\circ} \mathrm{C}$ após 24 horas (\%) } \\
\hline Soja & 72,2 & 70,2 & 72,7 & $71,7 \mathrm{~b}$ & \\
\hline Salmão & 74,2 & 74,4 & 76,0 & $74,8 \mathrm{a}$ & \\
\hline Média & 73,2 & 72,3 & 74,4 & & 11,2 \\
\hline \multicolumn{6}{|c|}{ Motilidade a $5^{\circ} \mathrm{C}$ após 24 horas } \\
\hline Soja & 65,2 & 63,2 & 65,7 & $64,7 \mathrm{~b}$ & \\
\hline Salmão & 67,2 & 67,4 & 70,0 & $67,8 \mathrm{a}$ & \\
\hline Média & 66,2 & 65,3 & 67,4 & & 12,4 \\
\hline \multicolumn{6}{|c|}{ Motilidade a $17^{\circ} \mathrm{C}$ após 48 horas (\%) } \\
\hline Soja & 68,2 & 66,2 & 68,7 & $67,7 \mathrm{~b}$ & \\
\hline Salmão & 70,2 & 70,4 & 72,0 & $70,8 \mathrm{a}$ & \\
\hline Média & 69,2 & 68,3 & 70,4 & & 11,9 \\
\hline \multicolumn{6}{|c|}{ Motilidade a $5^{\circ} \mathrm{C}$ após 48 horas } \\
\hline Soja & 55,2 & 53,2 & 55,7 & $54,7 \mathrm{~b}$ & \\
\hline Salmão & 61,2 & 61,4 & 63,0 & $61,8 \mathrm{a}$ & \\
\hline Média & 58,2 & 57,3 & 59,3 & & 14,1 \\
\hline \multicolumn{6}{|c|}{ Motilidade a $17^{\circ} \mathrm{C}$ após 72 horas (\%) } \\
\hline Soja & 65,2 & 63,2 & 65,7 & $64,7 b$ & \\
\hline Salmão & 67,2 & 67,4 & 70,0 & $67,8 \mathrm{a}$ & \\
\hline Média & 66,2 & 65,3 & 67,4 & & 12,4 \\
\hline \multicolumn{6}{|c|}{ Motilidade a $5^{\circ} \mathrm{C}$ após 72 horas } \\
\hline Soja & 44,2 & 42,2 & 44,7 & $43,7 \mathrm{~b}$ & \\
\hline Salmão & 50,2 & 50,4 & 52,0 & $50,8 \mathrm{a}$ & \\
\hline Média & 47,2 & 46,3 & 48,4 & & 17,4 \\
\hline
\end{tabular}

Médias seguidas de letras diferentes na mesma coluna diferiram $(\mathrm{P}<0,05)$ pelo teste SNK.

verificou-se que a adição de óleo de salmão (DHA) na ração promoveu alteração na composição da membrana espermática, o que pode ter contribuído para que a motilidade do sêmen resfriado a $5^{\circ} \mathrm{C}$, nas 24 e 48 horas, não reduzisse a valores muito baixos. A motilidade espermática é considerada um parâmetro importante na qualidade do sêmen de suíno, pois ejaculados com motilidade menor e igual a 60\% fertilizam poucos ovócitos (Britt et al., 1999; Johnson et al., 2000). Na composição de ácidos graxos dos espermatozoides a fresco, verificou-se maior motilidade no sêmen dos animais tratados com óleo de salmão e acondicionado a $5^{\circ} \mathrm{C}$ até 48 horas que os animais tratados com óleo de soja.

A suplementação com óleo de salmão aumentou $(\mathrm{P}<0,05)$ o vigor dos espermatozoides resfriado nas temperaturas estudadas após 24 e 48 horas de acondicionamento, não diferindo $(\mathrm{P}>0,05)$ após 72 horas (Tabela 5).

A porcentagem de espermatozoides reativos ao teste hiposmótico aumentou $(\mathrm{P}<0,05)$ com a adição de óleo de salmão na ração do sêmen resfriado para ambas as temperaturas nos períodos de armazenamento (Tabela 6).

Para as características espermáticas estudadas (motilidade, vigor e teste hiposmótico) a 17 e $5^{\circ} \mathrm{C}$, os valores 
Tabela 5 - Vigor espermático do sêmen de suínos sob suplementação com óleo e vitamina $\mathrm{E}$

\begin{tabular}{|c|c|c|c|c|c|}
\hline \multirow{2}{*}{$\begin{array}{l}\text { Tipo de } \\
\text { óleo }\end{array}$} & \multicolumn{3}{|c|}{ Nível de vitamina E (mg/kg) } & \multirow[b]{2}{*}{ Média } & \multirow[b]{2}{*}{ CV $(\%)$} \\
\hline & 150 & 300 & 450 & & \\
\hline & \multicolumn{3}{|c|}{ Vigor a $17^{\circ} \mathrm{C}$ após 24 horas } & & \\
\hline Soja & 4,47 & 4,17 & 4,25 & $4,30 \mathrm{~b}$ & \\
\hline Salmão & 4,40 & 4,42 & 4,45 & $4,42 \mathrm{a}$ & \\
\hline \multirow[t]{2}{*}{ Média } & 4,43 & 4,29 & 4,35 & & 14,1 \\
\hline & \multicolumn{3}{|c|}{ Vigor a $5^{\circ} \mathrm{C}$ após 24 horas } & & \\
\hline Soja & 3,40 & 3,17 & 3,25 & $3,30 \mathrm{~b}$ & \\
\hline Salmão & 3,40 & 3,42 & 3,45 & $3,42 \mathrm{a}$ & \\
\hline \multirow[t]{2}{*}{ Média } & 3,40 & 3,30 & 3,35 & & 20,0 \\
\hline & \multicolumn{3}{|c|}{ Vigor a $17^{\circ} \mathrm{C}$ após 48 horas } & & \\
\hline Soja & 4,14 & 4,12 & 4,15 & $2,14 b$ & \\
\hline Salmão & 4,24 & 4,17 & 4,35 & $2,25 \mathrm{a}$ & \\
\hline \multirow[t]{2}{*}{ Média } & 4,19 & 4,14 & 4,25 & & 20,0 \\
\hline & \multicolumn{3}{|c|}{ Vigor a $5^{\circ} \mathrm{C}$ após 48 horas } & & \\
\hline Soja & 2,60 & 2,65 & 2,64 & $2,63 b$ & \\
\hline Salmão & 2,86 & 2,71 & 2,66 & $2,74 \mathrm{a}$ & \\
\hline \multirow[t]{2}{*}{ Média } & 2,73 & 2,68 & 2,65 & & 18,5 \\
\hline & \multicolumn{3}{|c|}{ Vigor a $17^{\circ} \mathrm{C}$ após 72 horas } & & \\
\hline Soja & 2,50 & 2,65 & 2,50 & 2,55 & \\
\hline Salmão & 2,45 & 2,62 & 2,55 & 2,54 & \\
\hline \multirow[t]{2}{*}{ Média } & 2,47 & 2,64 & 2,52 & & 19,6 \\
\hline & \multicolumn{3}{|c|}{ Vigor a $5^{\circ} \mathrm{C}$ após 72 horas } & & \\
\hline Soja & 2,16 & 2,11 & 2,16 & 2,14 & \\
\hline Salmão & 2,10 & 2,15 & 2,14 & 2,13 & \\
\hline Média & 2,13 & 2,13 & 2,15 & & 26,3 \\
\hline
\end{tabular}

Médias seguidas de letras diferentes na mesma linha/coluna diferiram pelo teste SNK $(\mathrm{P}<0,05)$.

observados diferiram $(\mathrm{P}<0,05)$ em relação ao período em que foram acondicionados, em que os valores observados no período de 24 horas foram superiores aos de 48 horas, os quais, por sua vez, foram superiores aos de 72 horas.

A morfologia anormal total observada neste estudo aumentou $(\mathrm{P}<0,05)$ no sêmen dos animais tratados com óleo de soja e resfriados a $17^{\circ} \mathrm{C}$. Não foi observada diferença $(\mathrm{P}>0,05)$ entre os animais suplementados em relação ao sêmen resfriado a $5^{\circ} \mathrm{C}$ (Tabela 7). Entretanto, a porcentagem de defeitos totais foi maior $(\mathrm{P}<0,05)$ no sêmen acondicionado a $5^{\circ} \mathrm{C}$ que a $17^{\circ} \mathrm{C}$, para todos os momentos avaliados. Os resultados registrados corroboram com os de Roner et al. (2005) para as temperaturas de 17 e $5^{\circ} \mathrm{C}$, respectivamente, após 24 e 48 horas.

Nenhuma curva de resfriamento foi realizada para o sêmen submetido ao resfriamento a $5^{\circ} \mathrm{C}$. Embora se saiba que um resfriamento mais rápido implica maiores lesões aos espermatozoides, o sêmen mantido a $5^{\circ} \mathrm{C}$ apresentou, de modo geral, índices de viabilidade (motilidade, morfologia e Host $)$ inferior $(\mathrm{P}<0,05)$ ao sêmen mantido a $17^{\circ} \mathrm{C}$. Ainda hoje, não está bem definida qual é a velocidade de resfriamento adequada para o armazenamento do sêmen suíno em temperaturas abaixo de $17^{\circ} \mathrm{C}$. Pressupõe-se que
Tabela 6 - Teste hiposmótico do sêmen de suínos sob suplementação com óleo e vitamina E

\begin{tabular}{|c|c|c|c|c|c|}
\hline \multirow{2}{*}{$\begin{array}{l}\text { Tipo de } \\
\text { óleo }\end{array}$} & \multicolumn{3}{|c|}{ Nível de vitamina $E(\mathrm{mg} / \mathrm{kg})$} & \multirow[b]{2}{*}{ Média } & \multirow[b]{2}{*}{$\mathrm{CV}(\%$} \\
\hline & 150 & 300 & 450 & & \\
\hline \multicolumn{6}{|c|}{ Teste hiposmótico a $17^{\circ} \mathrm{C}$ após 24 horas } \\
\hline Soja & 79,7 & 78,6 & 79,6 & $79,3 \mathrm{~b}$ & \\
\hline Salmão & 85,5 & 84,2 & 83,6 & $84,4 \mathrm{a}$ & \\
\hline Média & 82,6 & 81,4 & 81,6 & & 5 \\
\hline
\end{tabular}

Teste hiposmótico a $5^{\circ} \mathrm{C}$ após 24 horas

Soja $\quad 60,3 \quad 61,2 \quad 60,3 \quad 60,6 \mathrm{~b}$

Salmão $\quad 72,2 \quad 72,0 \quad 71,7 \quad 72,0 \mathrm{a}$

Média $\quad 66,3 \quad 66,7 \quad 66,0 \quad 7,3$

Teste hiposmótico a $17{ }^{\circ} \mathrm{C}$ após 48 horas

$\begin{array}{lccccc}\text { Soja } & 68,7 & 67,7 & 68,6 & 68,3 \mathrm{~b} & \\ \text { Salmão } & 74,5 & 73,2 & 72,6 & 73,4 \mathrm{a} & \\ \text { Média } & 71,6 & 70,4 & 70,6 & & 6,41\end{array}$

$\begin{array}{lcccr} & \text { Teste hiposmótico a } 5^{\circ} \mathrm{C} \text { após } 48 \text { horas } \\ \text { Soja } & 52,3 & 53,3 & 52,3 & 52,6 \mathrm{~b} \\ \text { Salmão } & 64,2 & 64,0 & 63,7 & 64,0 \mathrm{a}\end{array}$

Média $\quad 58,3 \quad 58,7 \quad 58,0 \quad 8,3$

Teste hiposmótico a $17^{\circ} \mathrm{C}$ após 72 horas

$\begin{array}{llllll}\text { Soja } & 62,7 & 61,6 & 62,6 & 62,3 \mathrm{~b} & \\ \text { Salmão } & 68,5 & 67,2 & 66,6 & 67,4 \mathrm{a} & \\ \text { Média } & 65,6 & 64,4 & 64,6 & & 7,0\end{array}$

Teste hiposmótico a $5^{\circ} \mathrm{C}$ após 72 horas

$\begin{array}{llllll}\text { Soja } & 46,3 & 47,3 & 46,3 & 46,6 \mathrm{~b} & \\ \text { Salmão } & 58,2 & 58,0 & 57,7 & 58,0 \mathrm{a} & \\ \text { Média } & 52,3 & 52,7 & 52,0 & & 9,2\end{array}$

Médias seguidas de letras diferentes na mesma coluna diferiram $(\mathrm{P}<0,05)$ pelo teste SNK.

um resfriamento lento pode amenizar os efeitos deletérios do choque térmico pelo frio. Segundo Watson \& Plummer(1985), a velocidade de resfriamento influencia decisivamente no efeito do choque térmico sobre os espermatozoides.

Comparando os valores registrados neste estudo para motilidade, teste hiposmótico e morfologia aos de Juliano et al. (2005), que avaliaram a qualidade do sêmen armazenado com BTS e PIGPEL-5 em diferentes temperaturas (17 e $5^{\circ} \mathrm{C}$ ), constataram-se valores maiores quanto à motilidade e à morfologia espermática anormal apenas quando o diluente utilizado foi o BTS, sendo os valores deste estudo inferiores aos do PIGPEL-5. Há resultados contraditórios com relação ao diluente PIGPEL-5, que foi desenvolvido especificamente para ser utilizado em sêmen suíno a ser resfriado a $5^{\circ} \mathrm{C}$. Isso pode estar relacionado a diferenças em relação a fatores genéticos ou de meio. No entanto, vale ressaltar que os valores alcançados neste estudo aproximaram-se aos do diluente específico para as temperaturas de $5^{\circ} \mathrm{C}$. Seria interessante avaliar a fertilidade do sêmen e estudar qual seria mais viável economicamente de se utilizar.

Não foi observado efeito dos níveis de vitamina $\mathrm{E}$ $(\mathrm{P}>0,05)$, nem interações desta com as fontes de óleo na 
Tabela 7 - Morfologia anormal do sêmen de suínos sob suplementação com óleo e vitamina $\mathrm{E}$

\begin{tabular}{|c|c|c|c|c|c|}
\hline \multirow{2}{*}{$\begin{array}{c}\text { Tipo de } \\
\text { óleo }\end{array}$} & \multicolumn{3}{|c|}{ Nível de vitamina $\mathrm{E}(\mathrm{mg} / \mathrm{kg})$} & \multirow[b]{2}{*}{ Média } & \multirow[b]{2}{*}{ CV $(\%)$} \\
\hline & 150 & 300 & 450 & & \\
\hline \multicolumn{6}{|c|}{ Defeitos totais a $17^{\circ} \mathrm{C}$ após 24 horas } \\
\hline Soja & 4,75 & 4,62 & 5,12 & $4,83 \mathrm{a}$ & \\
\hline Salmão & 3,56 & 3,75 & 3,62 & $3,64 b$ & \\
\hline Média & 4,16 & 4,62 & 5,12 & & 39,7 \\
\hline \multicolumn{6}{|c|}{ Defeitos totais a $5^{\circ} \mathrm{C}$ após 24 horas } \\
\hline Soja & 9,0 & 9,62 & 8,12 & $8,92 \mathrm{a}$ & \\
\hline Salmão & 8,5 & 8,0 & 8,12 & $8,20 \mathrm{a}$ & \\
\hline Média & 8,75 & 8,81 & 8,12 & & 26,0 \\
\hline \multicolumn{6}{|c|}{ Defeitos totais a $17^{\circ} \mathrm{C}$ após 48 horas } \\
\hline Soja & 8,75 & 8,62 & 9,12 & $8,83 \mathrm{a}$ & \\
\hline Salmão & 7,56 & 7,75 & 7,62 & $7,64 b$ & \\
\hline Média & 8,15 & 8,19 & 8,37 & & 20,4 \\
\hline \multicolumn{6}{|c|}{ Defeitos totais a $5^{\circ} \mathrm{C}$ após 48 horas } \\
\hline Soja & 11,0 & 11,62 & 10,16 & $10,93 \mathrm{a}$ & \\
\hline Salmão & 10,5 & 9,97 & 10,0 & $10,15 \mathrm{a}$ & \\
\hline Média & 10,75 & 10,80 & 10,08 & & 20,6 \\
\hline \multicolumn{6}{|c|}{ Defeitos totais a $17^{\circ} \mathrm{C}$ após 72 horas } \\
\hline Soja & 9,75 & 9,62 & 10,12 & $9,83 \mathrm{a}$ & \\
\hline Salmão & 8,56 & 8,75 & 8,62 & $8,64 \mathrm{~b}$ & \\
\hline Média & 9,16 & 9,19 & 9,37 & & 18,2 \\
\hline \multicolumn{6}{|c|}{ Defeitos totais a $5^{\circ} \mathrm{C}$ após 72 horas } \\
\hline Soja & 13,5 & 14,31 & 12,72 & $13,51 \mathrm{a}$ & \\
\hline Salmão & 13,37 & 12,97 & 12,75 & $13,03 \mathrm{a}$ & \\
\hline Média & 13,44 & 13,64 & 12,73 & & 14,2 \\
\hline
\end{tabular}

Médias seguidas de letras diferentes na mesma coluna diferiram $(\mathrm{P}<0,05)$ pelo teste SNK.

dieta para todas as variáveis estudadas. Como não houve perdas na qualidade seminal nem aumento da morfologia anormal espermática, pode-se inferir que os níveis utilizados tiveram a função antioxidante desejada. Marin-Guzman et al. (1997, 2000) constataram que o nível 220 UI na ração de suínos melhorou a qualidade animal, pois esse nível de vitamina $\mathrm{E}$ teve um papel de proteger os espermatozoides contra danos oxidativos.

\section{Conclusões}

À exceção do vigor avaliado às 72 horas, a adição de óleo de salmão melhora as características espermáticas de motilidade e os resultados do teste hiposmótico do sêmen suíno resfriado a 17 e $5^{\circ} \mathrm{C}$ durante o período de acondicionamento.

\section{Agradecimentos}

Ao $\mathrm{CNPq}$, pela bolsa de doutorado; à Perdigão Agroindustrial S/A; à MINITUB do Brasil; e Lagoa da Serra Ltda, pelo apoio logístico, sem o qual este trabalho não seria realizado.

\section{Referências}

BLESBOIS, E.; LESSIRE, M.; GRASSEAU, I. et al. Effect of dietary fat on the fatty acid composition and fertilizing ability of fowl semen. Biology of Reproduction, v.56, p.1216-1220, 1997.

BUHR, M.M.; CURTIS, E.F.; KAKUDA, S. Composition and behavior of head membrane lipids of fresh and cryopreserved boar sperm. Cryobiology, v.31, p.224-238, 1994.

BRITT, J.H.; ALMOND, G.W.; FLOWERS, W.L. Diseases of the reproductive system. In: STRAWS, B.; D'ALLAIRE, S.; MENGELING, W.; TAYLOR, D. (Eds.) Diseases of swine. 8.ed. Ames: Blackwell Sciences Ltda, 1999. p.905.

COLÉGIO BRASILEIRO DE REPRODUÇÃO ANIMAL - CBRA Manual para exame andrológico e avaliação de sêmen animal. 2.ed. Belo Horizonte: 1998. 49p. (Manual).

CORRÊA, M.N.; BIANCHI, I.; LUCIA JR., T. et al. Efeito do diluente PIGPEL-5 sobre alguns parâmetros da avaliação de sêmen suíno acondicionado a $5^{\circ} \mathrm{C}$. In: CONGRESSO BRASILEIRO DE VETERINÁRIOS ESPECIALISTAS EM SUÍNOS, 7., 2005, Fortaleza. Anais... Fortaleza: ABRAVES, 2005. p.279-280.

DE LEEUW, F.E.; COLENBRANDER, B.; VERKLEIJ, A.J. The role membrane damage plays in cold shock and freezing injury. Reproduction in Domestic Animals, Suppl.1, p.95-104, 1991.

FERREIRA NETO, J.M.; VIANA, E.S.; MAGALHÃES, L.M Patologia clínica veterinária. Belo Horizonte: Rabelo Brasil, 1977. 279p.

FIRESTONE, D. Official methods and recommended practices of the American Oil Chemists Society. 5.ed. Champaign: AOCS, 1998. p.372-373.

FOLCH, J.; LESS, M.; STANLEY, S. A simple method for the isolation and purification of total lipids from animal tissues Journal of Biological Chemical, v.226, n.1, p.497-509, 1957.

JOHNSON, L.A.; WEITZE, K.F.; FISER, P. et al. Storage of boar semen. Animal Reproduction Science, v.62, p.143-172, 2000 .

JULIANO, F.; BIANCHI, I.; CORRÊA, M.N. et al. Efeito do diluente PIGPEL-5 com distintos crioprotetores no sêmen suíno resfriado, armazenado em geladeira e caixas refrigeradoras a $5^{\circ} \mathrm{C}$ e $17^{\circ} \mathrm{C}$. In: CONGRESSO BRASILEIRO DE VETERINÁRIOS ESPECIALISTAS EM SUÍNOS, 7., 2005, Fortaleza. Anais... Fortaleza: ABRAVES, 2005. p.287-288.

KATZER, L.H.; BERNARDI, M.L.; BORTOLOZZO, F.P. et al. Viabilidade de sêmen suíno armazenamento a $5^{\circ} \mathrm{C}$ de acordo com a taxa de resfriamento e incubação prévia. Ciência Rural, v.35, n.1, p.138-144, 2005.

KING, G.J.; MACPHERSON, J.W. A comparison of two methods for boar semen collection. Journal of Animal Science, v.36, n.4, p.563-565, 1973.

KUMI-DIAKA, J. Subjecting canine semen to the hypoosmotic test. Theriogenology, v.39, p.1279-1289, 1993.

LANDSVERK, K. Packaging and distribution - their impact on fertility. In: INTERNATIONAL CONFERENCE ON BOAR SEMEN PRESERVATION, 4., 1999, Beltsville, Maryland. Proceedings... Lawrence: Allen, 2000. p.137-139. 280p.

MARIN-GUZMAN, J.; MAHAN, D.C.; WHITMOYER, R. Effects of dietary selenium and vitamin $\mathrm{E}$ on the ultrastructure and ATP concentration of boar spermatozoa, and the efficacy of added sodium selenite in extended semen on sperm motility. Journal of Animal Science, v.78, p.1544-1550, 2000.

MARIN-GUZMAN, J.; MAHAN, D.C.; CHUNG, Y.K. et al. Effects of dietary selenium and vitamin $\mathrm{E}$ on boar performance and tissue responses, semen quality and subsequent fertilization rates in mature gilts. Journal of Animal Science, v.75, p.2994-3003, 1997.

NATIONAL RESEACH COUNCIL - NRC. Nutrient requirements of swine. 10.ed. Washington: National Academy of Science, 1998. 189p. 
PURSEL, V.G.; JOHNSON, L.A.; SCHULMAN, L.L. Interaction of extender composition and incubation period on cold shock susceptibility of boar spermatozoa. Journal of Animal Science, v.35, n.3, p.580-584, 1972.

RONER, M.N.B.; PALHARES, M.S.; SILVA FILHO, J.M. et al. Qualidade espermática do sêmen suíno submetido a um sistema de refrigeração e conservação a $17^{\circ} \mathrm{C}$ e $5^{\circ} \mathrm{C}$. In: CONGRESSO BRASILEIRO DE VETERINÁRIOS ESPECIALISTAS EM SUÍNOS, 12., 2005, Fortaleza. Anais... Fortaleza: ABRAVES, 2005. p.295-296.

ROOKE, J.A., SHAO, C.C., SPEAKE, B.K. Effects of feeding tuna oil on the lipid composition of pig spermatozoa and in vitro characteristics of semen. Reproduction, v.121, p.315-322, 2001.

TAMULI, M.K.; WATSON, P.F. Cold resistance of live boar spermatozoa during incubation after ejaculation. Veterinary Record, v.135, n.7, p.160-162, 1994.

UNIVERSIDADE FEDERAL DE VIÇOSA - UFV. Manual de utilização do programa SAEG (Sistema para Análise Estatística e Genéticas). Viçosa, MG: 1997. 149p.

VAZQUEZ, J.M.; MARTINEZ, E.A.; GARCIA-ARTIGA, C. et al. Hypoosmotic swelling of boar spermatozoa compared to other methods for analysing the sperm membrane. Theriogenology, v.47, p.913-922, 1997.
WATSON, P.F.; GREEN, C.E. Cooling and capacitation of boar spermatozoa: What do they have in common? In: INTERNATIONAL CONFERENCE OF BOAR SEMEN PRESERVATION, 4., 2000, Beltsville, Maryland - USA. Proceedings... 2000. p.35-41.

WATSON, P.F.; PLUMMER, J.M. The responses of boar sperm membranes to cold shock and cooling. In: CONFERENCE. ON DEEP FREEZING OF BOAR SEMEN, 1985, Uppsala. Proceedings... Uppsala: Swedish University of Agriculture Sciences, 1985. p.113-127.

WATSON, P.F. Cooling of spermatozoa and fertilizing capacity. Reproduction in Domestic Animals, v.31, n.1, p.135-140, 1996.

WEBER, H. Zur Kälteschockempfindlichkeit von Eberspermien; Einflub von Verdünnermedium, Inkubation und Abkühlrate. 1989. 103f. Tese (Doutorado em Reprodução de Suínos) - Escola Superior de Veterinária de Hannover, Alemanha.

WEITZE, K.F.; WEBER, H.; WABERSKI, D. Influence of incubation time and cooling rate on chilling sensitivity of diluted boar semen. In: INTERNATIONAL CONFERENCE ON BOAR SEMEN PRESERVATION. 4., 1999, Beltsville, Maryland. Proceedings... Lawrence: Allen, 2000. p.264. 